\title{
Tantangan Indonesia Untuk Mengoptimalisasikan Bonus
}

\section{Pengantar}

Indonesia memilikspqippran yang besar, terbesar keempat setelah Cina, India dan Amerika Serikat. Penduduk Indonesia yang mengalami peningkatan dari tahun ke tahun, berdasarkan proyeksi BPS pada tahun 2035 mendatang berjumlah 305,6 juta jiwa. Jumlah ini meningkat $28,14 \%$ dari tahun 2010 yang sebesar 238,5 juta jiwa ${ }^{1}$. Pertambahan jumlah penduduk ini dapat memunculkan dua implikasi, negatif dan positif. Implikasi pertama, peningkatan jumlah penduduk dianggap sebagai sesuatu yang problematis karena pertumbuhan penduduk yang terus membesar akan berkorelasi dengan berbagai hal yang diasosiasikan dengan hal negatif, misalnya di sektor perekonomian muncul banyak pengangguran,

kriminalitas, dan dalam konteks sosial, pertumbuhan penduduk dapat memicu aksi urbanisasi, serta berbagai masalah lainnya. Tetapi jumlah penduduk yang besar tidak selalu memiliki asosiasi negatif namun bisa memberikan implikasi positif. Sebagai contoh, tren meningkatnya pertumbuhan penduduk di Indonesia hingga tahun 2035 justru diprediksikan menghasilkan dampak positif. Penyebabnya, peningkatan jumlah penduduk Indonesia tersebut dibarengi dengan meningkatnya penduduk berusia produktif (usia 15 tahun sampai 65 tahun). Tabel 1 di bawah ini adalah gambaran mengenai proyeksi profil kependudukan (baca: demografi) dengan besarnya penduduk berusia 15 sampai 65 tahun.

\footnotetext{
${ }^{1}$ Proyeksi Penduduk Indonesia 2010-2035:24
} 


\section{Tabel 1}

Proyeksi Demografi Indonesia, 2010-2035

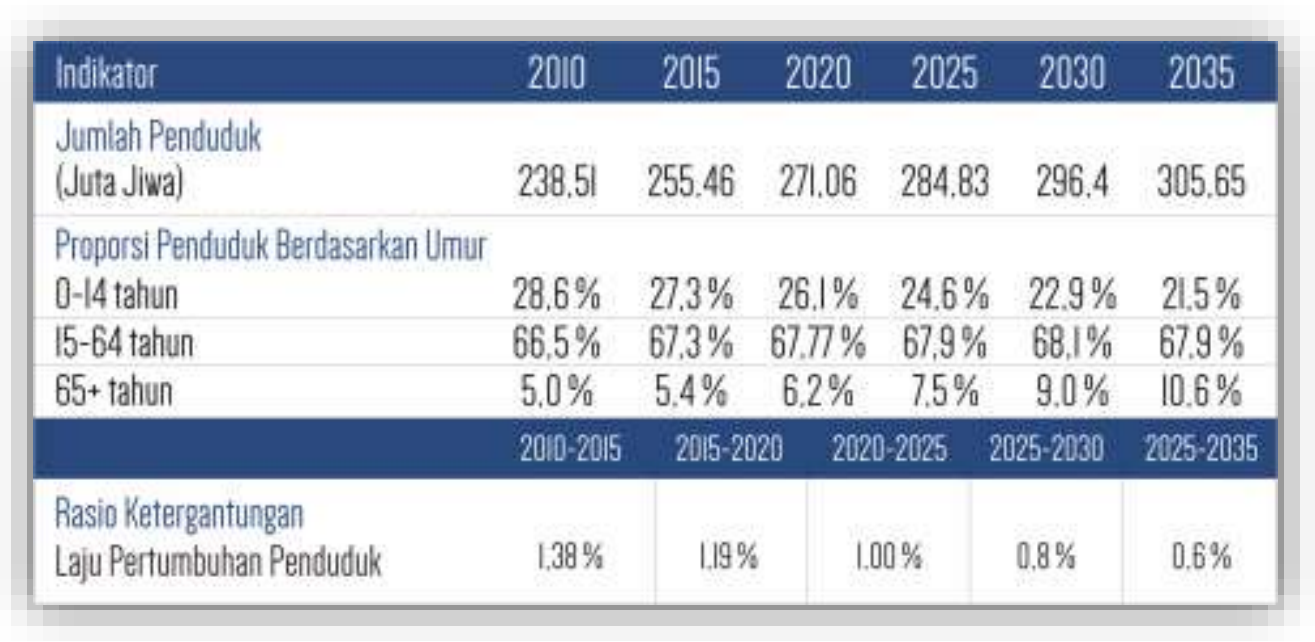

Sumber: Statistic Proyeksi Penduduk Indonesia 2010-2035

Tabel 1 tersebut menjelaskan tentang tiga aspek penting. Pertama, jumlah penduduk yang meningkat secara umum. Kedua, bertambahnya jumlah penduduk tersebut diikuti dengan meningkatnya proporsi penduduk yang berusia 15-64 tahun, yang artinya persentase penduduk produktif juga menguat. Ketiga, implikasinya adalah menurunnya angka rasio ketergantungan penduduk dalam profil demografi di Indonesia. Dengan kata lain, perubahan tiga indikator demografi seperti yang terlihat pada tabel 1 di atas akan berdampak pada berubahnya struktur demografi di Indonesia. Perubahan struktur demografi yang dimaksud pada Tabel 1 adalah meningkatnya proporsi usia produktif, yaitu kelompok umur 15-64 tahun. Indonesia mengalami struktur demografi yang memiliki proporsi penduduk umur 15-64 tahun lebih besar secara signifikan dibandingkan dengan kelompok umur lainnya.

Secara teoritis, bonus demografi (demographic dividend) memberikan

\footnotetext{
2 Indonesia's Intergovernmental Transfer: Response on Future Demographic and Urbanization Shifts, DSFDecentralization Support Facility, Nov-2014: Bab I
}

keuntungan secara ekonomis bagi sebuah negara karena rasio ketergantungannya menurun dan diikuti kenaikan penduduk usia produktif. Studi yang dilakukan Bloom et.al (1999) serta Bloom dan Finlay (2009) menyebutkan bahwa bonus demografi telah dinikmati oleh negara-negara di kawasan Asia Timur seperti Cina, Jepang dan Korea yang ditandai dengan tingginya tingkat pertumbuhan pendapatan perkapita ${ }^{2}$. Sebagian negara-negara Asia telah berhasil membangun menjadi negara industri dengan memanfaatkan bonus demografi. Mereka adalah Korea Selatan, Jepang, Taiwan, Hong Kong. Sementara Pakistan dan India tidak berhasil menangkap peluang bonus demografi itu ${ }^{3}$.

Apabila negara-negara di Asia Timur telah mampu menangkap peluang adanya demographic devidend, lalu bagaimana potensi bonus demografi nantinya bagi bangsa Indonesia? Apakah bonus demografi yang terjadi akan mampu menjadi lompatan menuju negara berpenghasilan tinggi, atau

http://bisnis.liputan6.com/read/2307067/indonesiaharus-manfaatkan-bonus-demografi-seperti-korsel 
apakah bonus demografi tersebut dapat mendorong akselerasi menuju negara industri? Atau bonus demografi yang akan terjadi justru menimbulkan problema? Ada sejumlah indikator yang dapat dijadikan acuan untuk mempersiapkan bonus demografi agar mampu menjadikan Indonesia menuju transformasi pembangunan ekonomi. Hal yang terpenting adalah mempersiapkan bonus demografi tersebut menjadi sumberdaya manusia yang memiliki daya saing, yaitu melalui pendidikan dan pelatihan. Pendidikan dan pelatihan ini tentu saja tidak dapat berhasil jika tidak didukung situasi ekonomi politik yang kondusif. Sehingga situasi ekonomi politik yang kondusif menjadi prasyarat penting agar pendidikan dan pelatihan mampu menjadikan usia produktif menjadi bonus demografi.

\section{Indikator Pendidikan Sebagai Variabel Penting Pembangunan SDM}

Tulisan ini akan mendiskusikan daya saing sumberdaya manusia saat ini, untuk kemudian sebagai tolok ukur atau acuan agar bonus demografi di masa depan tidak kehilangan momentumnya. Untuk mengawali tulisan ini, akan ditampilkan ilustrasi profil ketenagakerjaan menurut tingkat pendidikannya. Salah satunya penelitian mengenai hal tersebut telah dilakukan oleh FEB UI pada tahun $2015^{4}$. Penelitian tersebut membahas tentang bonus demografi dan kesempatan yang memacu percepatan industri di Indonesia dengan memanfaatkan data BPS tahun 2011. Secara spesifik penelitian ini menganalisis penduduk yang bekerja yaitu 15 tahun ke atas diperbandingkan dengan tingkat pendidikannya. Hasil penelitian ini menunjukkan bahwa pekerja masih didominasi oleh lulusan SD ke bawah, yaitu sebanyak 54,2 juta orang dengan persentase 49,40\%. Artinya hingga tahun 2014 (menjelang MEA), profil ketenagakerjaan masih didominasi oleh tenaga kerja yang tidak berpendidikan tinggi. Ilustrasi profil ketenagakerjaan dari penelitian FEB UI ini akan dikonfirmasi dengan data yang lebih detil seperti Tabel 2.

Tabel 2

Penduduk Usia 15 tahun ke atas yang bekerja menurut Pendidikan Tertinggi yang Ditamatkan, 2010-2014 (juta orang)

\begin{tabular}{|l|l|l|l|l|}
\hline & $\mathbf{2 0 1 0}$ & $\mathbf{2 0 1 1}$ & $\mathbf{2 0 1 2}$ & $\mathbf{2 0 1 4}^{*}$ \\
\hline SD ke bawah & 54,51 & 54,18 & 55,51 & 45,3 \\
\hline Sekolah Menengah Pertama & 20,63 & 20,7 & 20,29 & 18,5 \\
\hline Sekolah Menengah Atas & 15,92 & 17,11 & 17,2 & 16,2 \\
\hline Sekolah Menengah Kejuruan & 8,88 & 8,86 & 9,43 & 9,1 \\
\hline Diploma I, II, III & 3,02 & 3,17 & 3,12 & 3,8 \\
\hline Universitas & 5,25 & 5,65 & 7,25 & 7,1 \\
\hline
\end{tabular}

Sumber: Keadaan Ketenagakerjaan Februari 2012 (bag.2) | data-tnp2k, tahun 2014 sumber dari Statistik Indonesia 2015: 88

Tabel 2 menunjukkan bahwa selama periode tahun 2010-2014 tingkat pendidikan tenaga kerja di Indonesia masih didominasi oleh

\footnotetext{
4 Analisis Bonus Demografi Sebagai Kesempatan Memacu Perpercepatan Industri di Indonesia,
}

tingkat pendidikan SD. Pada tahun 2012, tenaga kerja yang berpendidikan Sekolah Menengah Pertama sebesar 20,3 juta (17,99

Departemen Kajian dan Aksi Strategis BEM FEB UI 2015 
persen). Sementara itu, pekerja yang berpendidikan tinggi hanya sekitar 10,3 juta orang mencakup 3,1 juta orang (2,77 persen) berpendidikan diploma dan 7,2 juta orang (6,43 persen) berpendidikan universitas. Kondisi tersebut tidak berubah hingga tahun 2014.
Mengapa demikian? Situasi ketenagakerjaan yang masih didominasi oleh berpendidikan rendah berkaitan dengan tingkat pendidikan masyarakat. Tabel 3 menampilkan tingkat pendidikan penduduk Indonesia pada periode 1995-2013.

Tabel 3

\section{Indikator Pendidikan}

\begin{tabular}{|c|c|c|c|c|c|}
\hline & $\mathbf{1 9 9 5}$ & $\mathbf{2 0 0 0}$ & $\mathbf{2 0 0 5}$ & $\mathbf{2 0 1 0}$ & $\mathbf{2 0 1 3}$ \\
\hline SD/MI & 91,45 & 92,28 & 93,25 & 94,72 & 95,52 \\
\hline SMP/MTs & 50,96 & 60,27 & 65,37 & 67,62 & 73,73 \\
\hline SM/MA & 32,60 & 39,33 & 43,50 & 45,48 & 54,12 \\
\hline PT & 7,15 & 7,95 & 8,71 & 11,01 & 18,08 \\
\hline
\end{tabular}

Sumber: BPS-RI, Susenas 1994-2013

Keterangan: Mulai tahun 2007 dan tahun-tahun berikutnya APK mencakup pendidikan non formal (paket A setara SD/MI, paket B setara SMP/MTs dan paket C setara SM/SMK/MA)

Tabel 3 secara jelas memperlihatkan bahwa tingkat pendidikan penduduk di Indonesia adalah sebagian besar masih SMP ke bawah. Semakin tinggi tingkat pendidikan maka justru semakin rendah APMnya. Hal ini tentu saja sangat terkait dengan tabel 2 menunjukkan bahwa penduduk yang bekerja tidak memiliki tingkat pendidikan yang memadai

\section{Mengapa Kondisi Ketenagakerjaan Memprihatinkan Jika Dikaitkan dengan Isu Globalisasi}

Masyarakat usia produktif adalah faktor utama penggerak kehidupan ekonomi suatu negara. Kaum muda yang cerdas dan kreatif mampu menjadi engine of growth bagi perekonomian. Oleh sebab itu kelompok usia ini harus dipersiapkan secara tepat agar mampu menjadi engine of development.
Mempersiapkan generasi pada era sekarang ini akan lebih berat, mengapa? Secara umum ada dua argumen yang menjadikan dasar bahwa kompetisi yang dihadapi menjadi lebih kompleks. Pertama, situasi domestik. banyaknya usia produktif maka diantara mereka sendiri berkompetisi untuk memperebutkan pekerjaan yang tepat. Kedua, situasi global. Era globalisasi yang membawa arus tenaga kerja melintasi batasbatas geografis maka setiap usia produktif harus memilki daya saing tinggi.

Posisi sumber daya manusia Indonesia dibandingkan negara ASEAN plus setidaknya dapat dilihat dari 2 indikator yakni Global Talent Competitiveness Index serta Global Innovation Index. Setidaknya ada dua indikator yang menggambarkan kapasitas sumberdaya manusia dalam konteks global, yaitu Global Talent 
Competitivenes Index (GTCI) dan Global Innovation Index (GII).

\section{a. Global Talen Competitiveness Index}

GTCI adalah indeks komposit yang mengukur kemampuan negara dalam mengembangkan sumberdaya manusia agar memiliki talenta dalam inovasi dan pengembangan ekonomi. GTCI mencoba menawarkan pendekatan terhadap isu-isu daya saing sumber daya manusia berbakat secara komprehensif, dengan menggabungkan aspek-aspek gagasan, analisis dan praktis.

Table 3 Global Talent Competitiveness Index, 2015

ASEAN Plus

\begin{tabular}{|l|l|l|l|}
\hline No & \multicolumn{1}{|c|}{ Country } & Score (0-100) & $\begin{array}{c}\text { Peringkat dari } \\
\text { 109 negara }\end{array}$ \\
\hline 1 & Singapore & 71,456 & 2 \\
\hline 2 & Malaysia & 54,039 & 30 \\
\hline 3 & Filipina & 44,229 & 56 \\
\hline 4 & Thailand & 40,985 & 69 \\
\hline 5 & Brunei Darrusallam & - & - \\
\hline 6 & Vietnam & 37,728 & 82 \\
\hline 7 & Indonesia & 34,365 & 90 \\
\hline 8 & Kamboja & 33,082 & 96 \\
\hline 9 & Laos $*$ & - & - \\
\hline 10 & Myanmar* & - & - \\
\hline 11 & Jepang & 60,978 & 19 \\
\hline 12 & Korea & 52,448 & 37 \\
\hline 13 & India & 34,365 & 89 \\
\hline 14 & Cina & 46,600 & 48 \\
\hline
\end{tabular}

Sumber: GTCI (2015:44-45), http://global-indices.insead.edu/, *data Laos dan Myanmar tidak tersedia

Berdasarkan GTCI, sumberdaya manusia Indonesia sulit bersaing karena nilai GTCI nya rendah, atau dengan kata lain sumber daya manusia Indonesia tidak cukup kompetitif. Kondisi ini menjadikan masyarakat Indonesia tidak mudah beradaptasi dengan penggunaan teknologi baru di dalam industri. Mengapa demikian? GTCI adalah indeks komposit yang dibangun dari indikator-indikator yang mengukur proses membangun ide, melalukan analisa hingga praktikum secara teknis. Proses itulah yang membentuk kemampuan atau talen seseorang. Sehingga ketika nilai GTCI maka menunjukkan bahwa kemampuan atau talennya rendah. Hal ini yang kemudian membuat kita kalah bersaing.

\section{a. Global Innovation Index}

Menurut teori the new form of competition, keunggulan suatu bangsa tidak lagi didasarkan atas comparative advantage tapi competitive advantage yang ditentukan oleh kualitas penduduknya (GTCI 2013:21). Hal ini memberikan implikasi bahwa negara yang tidak cukup kompetitif secara human capital. Maka akan terancam oleh masuknya profesional dari bangsa lain. Lalu bagaimana dengan kondisi di Indonesia? 
Dalam konteks globalisasi, selain GTCI, indeks yang mengukur daya saing (competitiveness) sebuah negara adalah GII. Mengapa indeks yang mengukur inovasi penting? Menurut publikasi dari INSEAD et.al $^{5}$, terdapat tiga argumen yang membentuk dasar pentingnya mengukur tingkat inovasi di negara-negara, yang akan dijelaskan sebagai berikut: Pertama, inovasi penting untuk mengarahkan kemajuan ekonomi dan daya saing bagi negara maju dan berkembang. Banyak pemerintah yang menempatkan inovasi pada pusat strategi pertumbuhan mereka. Kedua, definisi inovasi telah diperluas, tidak lagi terbatas pada R\&D laboratorium dan publikasi karya ilmiah. Inovasi, bisa dan lebih umum serta horisontal di alam, termasuk inovasi sosial dan inovasi model bisnis maupun teknis. Terakhir, pengakuan dan merayakan inovasi di pasar negara berkembang, dipandang sebagai hal yang penting untuk menginspirasi orangorang, terutama generasi berikutnya dari pengusaha dan inovator. Perbandingan antara nilai GII di beberapa negara tetangga Indonesia dapat dilihat pada tabel 4

Tabel 4 Global Innovation Index, 2014

\begin{tabular}{|l|l|l|l|}
\multicolumn{1}{|c|}{ Negara } & \multicolumn{1}{|c|}{ Skor GII } & $\begin{array}{c}\text { Ranking } \\
\text { jumlah } \\
\text { negara:143) }\end{array}$ & Rasio Efisiensi \\
\hline Singapura & 59,24 & 7 & 0,61 \\
\hline Korea & 55,27 & 16 & 0,78 \\
\hline Jepang & 52,41 & 21 & 0,69 \\
\hline Cina & 46,57 & 29 & 1,03 \\
\hline Malaysia & 45,60 & 33 & 0,74 \\
\hline Thailand & 39,28 & 48 & 0,76 \\
\hline Vietnam & 34,89 & 71 & 0,95 \\
\hline Indonesia & 31,81 & 87 & 0,96 \\
\hline Philipina & 29,87 & 100 & 0,81 \\
\hline Kamboja & 28,66 & 106 & 0,74 \\
\hline Myanmar & 19,64 & 140 & 0,71 \\
\hline
\end{tabular}

Sumber: Global Inovasi Index

Berdasarkan tabel GII di atas, Singapura yang paling kompetitif di kawasan Asia Tenggara, apalagi Singapura ditempatkan di peringkat yang lebih tinggi di GII dibandingkan dengan NIC di Asia, seperti Korea dan Jepang. Sementara itu, Malaysia berada di peringkat kedua setelah Singapura di kawasan Asia Tenggara. Indonesia berada pada peringkat 87 dari 143 negara. Sementara Singapura peringkat ketujuh, Malaysia berada pada peringkat 33 , Thailand peringkat 48, dan Vietnam pada peringkat 71.

\section{Kualitas Rendah ditengah Ketimpangan yang Semakin Melebar}

Di tengah daya saing tenaga kerja Indonesia yang masih memprihatinkan, ada faktor yang menjadikan usia produktif ini 
tidak dapat ditransformasikan menjadi instrumen peningkatan kesejahteraan masyarakat dan akselerasi pembangunan secara signifikan. Salah satu faktor tersebut adalah isu kemiskinan dan ketimpangan (inequality).

Tabel 5. Ketimpangan Pendapatan

\begin{tabular}{|l|l|l|l|l|}
\hline Distribusi Pendapatan & $\mathbf{2 0 1 0}$ & $\mathbf{2 0 1 1}$ & $\mathbf{2 0 1 2}$ & $\mathbf{2 0 1 3}$ \\
\hline $\begin{array}{l}\text { - 40\% penduduk dengan } \\
\text { pendapatan terendah }\end{array}$ & 19,75 & 19,56 & 18,05 & 16,88 \\
\hline $\begin{array}{l}\text { - 40\% penduduk dengan } \\
\text { pendapatan menengah }\end{array}$ & 38,10 & 35,67 & 36,48 & 34,18 \\
\hline $\begin{array}{l}\text {-20\% penduduk dengan } \\
\text { pendapatan tertinggi }\end{array}$ & 42,15 & 44,77 & 45,47 & 48,94 \\
\hline
\end{tabular}

Sumber : Survei Sosial Ekonomi Nasional, Modul Konsumsi 1999, 2002 dan 2005 (2003, 2004 dan 2006 hanya mencakup panel 10.000 rumah tangga, sedangkan 2007, 2008, 2009, dan 2010 mencakup panel 68.800 rumah tangga), Tahun 2011-2013 merupakan data Susenas Triwulan I dan Triwulan III (Maret dan September) dengan sampel 75.000 rumah tangga.

Data di atas menunjukkan bahwa dari tahun 2010 hingga tahun 2013, 20\% penduduk dengan pendapatan tertinggi menguasai makin besar dari pendapatan nasional yaitu, 42,15\%. Kondisi ini tentu saja dibarengi dengan kondisi yang tidak membahagiakan karena $40 \%$ penduduk yang berpenghasilan terendah semakin kecil menikmati pendapatan nasional yaitu 19,75 $\%$. Situasi ini tentu saja tidak menguntungkan sebagaimana dijelaskan dibawah ini:

\section{Mengapa Kondisi ini Krusial?}

Penulis memiliki asumsi bahwa persoalan demografis kurang dianggap sebagai persoalan yang strategis setelah era otonomi daerah. Hal ini bisa ditelusuri setidaknya dari argumen-argumen berikut: Pertama, otonomi daerah yang memunculkan pemilihan kepala daerah secara langsung, menjadikan kepala daerah lebih berfokus kepada program-program infrastruktur dan program lain yang hasilnya lebih cepat terlihat. Tetapi program-program tersebut belum tentu dipertimpangkan terhadap sejauh mana mampu menyelesaikan persoalan kependudukan di daerah. Kedua, jumlah penyuluh program $\mathrm{KB}$ makin berkurang drastis bahkan tenaga penyuluh yang tersisa tidak fokus menjalankan fungsi penyuluh KB sebagaimana pada orde baru. Dengan asumsi diatas bahwa bisa terjadi usia calon bonus demografi yang ada pada saat ini berasal dari golongan masyarakat yang kesulitan mendapatkan akses terhadap layanan $\mathrm{KB}$, yang disinyalir itu berasal dari masyarakat kelompok menengah kebawah. Oleh karena itu, ketika pemerintah kurang memperhatikan terhadap pengelolaan bonus demografi ini, maka dikhawatirkan bonus demografi tidak mampu menjadi engine of development tetapi justru malah menjadi malapetaka.

Argumen lain yang menjadikan situasi krusial diantaranya dengan dinamika sosial politik yang terkadang justru mendistorsi proses pembangunan. Kemudian common sense terhadap pentingnya bonus demografi sebagai engine of development belum terbentuk secara maksimal dalam skala nasional. Hal ini berimplikasi bahwa bonus demografi menjadi kurang diperhatikan. Keadaan tersebut yang selanjutnya 
menjadikan human capital di Indonesia tidak menggembirakan yang tercermin pada situasi ketenagakerjaan. Situasi ketenagakerjaan di
Indonesia hingga tahun 2017 ini masih didominasi oleh penduduk dengan tingkat pendidikan SLTP ke bawah (Tabel 6).

\section{Tabel 6}

Penduduk Berumur 15 tahun ke atas menurut Pendidikan Tertinggi yang Ditamatkan

\begin{tabular}{|l|r|r|r|r|}
\hline & \multicolumn{2}{|c|}{ Bekerja } & \multicolumn{2}{c|}{ Angkatan Kerja } \\
\hline Pendidikan Tinggi & Jumlah & Persentase & \multicolumn{1}{c|}{$\begin{array}{c}\text { Kngkatan } \\
\text { Kerja }\end{array}$} & Persentase \\
\hline Tidak/belum sekolah & 5187494 & 0.05 & 5262392 & 0.04 \\
\hline Tidak/belum tamat SD & 15815487 & 0.14 & 16205037 & 0.13 \\
\hline Sekolah Dasar (SD) & 32952556 & 0.29 & 34182208 & 0.28 \\
\hline $\begin{array}{l}\text { Sekolah Menengah } \\
\text { Pertama (SMP) }\end{array}$ & 20350838 & 0.18 & 21917676 & 0.18 \\
\hline $\begin{array}{l}\text { Sekolah Menengah } \\
\text { Atas (SMA) }\end{array}$ & 18579737 & 0.16 & 20542523 & 0.17 \\
\hline $\begin{array}{l}\text { Sekolah Menengah } \\
\text { Kejuruan (SMK) }\end{array}$ & 10520757 & 0.09 & 11853278 & 0.10 \\
\hline Diploma I/II/III & 2956780 & 0.03 & 3150297 & 0.07 \\
\hline Universitas & 8264377 & 0.07 & 8759520 & - \\
\hline TOTAL & 114628026 & - & 121872931 & 03 \\
\hline
\end{tabular}

\section{Sumber: Statistik Indonesia 2015: 88}

Situasi ketenagakerjaan di Indonesia hingga tahun 2015 sungguh memprihatinkan karena sebagian besar masih lulusan SMA ke bawah. Situasi seperti ini jelas di Indonesia belum terbentuk human capital yang memiliki daya saing dan mampu melakukan inovasi. Jika situasi seperti ini akan berlanjut ketika bangsa Indonesia menghadapi ledakan usia produktif nanti maka sangat berbahaya. Dengan kata lain jika Indonesia merespon situasi terjadinya ledakan usia produktif maka berhasil memanfaatkannya, yang kemudian mampu menjadi engine of growth. Akan tetapi jika Indonesia tidak mempersiapakan melalui pendidikan, pelatihan, kelompok ekosistem creative hub dengan situasi sosial politik yang mendukung maka Indonesia akan gagal memanfaatkannya. Dalam kasus yang ekstrim, hal ini dimungkinkan akan menyebabkan kriminalitas meningkat dan bahkan berpotensi menimbulkan radikalisme.

\section{Kesimpulan}


Sebagai penutup, dapat dijelaskan bahwa bonus demografi adalah peluang dan tantangan yang krusial bagi keberlanjutan bangsa Indonesia ke depan. Oleh karena itu untuk menghadapinya perlu peran serta dari banyak pihak seperti pemerintah, perguruan tinggi masyarakat dan stakeholder lainnya supaya ledakan penduduk pada tahun 2030 mampu menjadi anugerah bagi Indonesia.

\section{Daftar Pustaka}

Badan Pusat Statistik (2015), Statistik Proyeksi Penduduk Indonesia 20102035

Bloom, D.E., D. Caning, L. Rosenberg, 2011. "Demographic Change and Economic Growth in South Asia. "PGDA Working Paper No. 67, February.

Bloom, D.E. and J.E. Finlay, 2009. "Demographic Change and Economic Growth in Asia." Asian Economic Policy Review (4), p.45-64.

Bloom, David E.; David Canning \& Jaypee Sevilla (2001), Economic Growth and the Demographic Transition, (working paper),

http://www.nber.org/papers/w8685.pd f..

Bloom, D. E., D. Canning, dan P.N. Malaney, 1999. "Demographic Change and Economic Growth in Asia. "CID Working Paper No. 15.

Bloom, David E dan Williamson 1997. "Demographic Transitions and Economic Miracles in Emerging Asia", (working paper) http://www.nber.org/papers/w6268.

Bloom, David E.; David Canning \& Jaypee Sevilla. 2003. The demographic dividend: a new perspective on the economic consequences of population change. Santa Monica CA, RAND Population Matters Program MR-1274.

Fathin, C.A., Arika B.P., Ayu K, Dyah Ratih S., Indonesian Human Resources Readiness in term of Facing the ASEAN Economic Community dalam JSP -
Jurnal Ilmu Sosial dan Ilmu Politik Vol 18 No. 2, Nov 2014 : 97-114.

Huggins, R., Izushi, H., Davies, W., \& Shougui, L. (2008). World Knowledge Competitiveness Index 2008. Cardiff, UK:

Lanvin, Bruno dan Evans, Paul (ed). INSEAD Singapura (2015). The Global Talent Competitiveness 20152016. diakses dari: http://globalindices.insead.edu/gtci/documents/INS EAD_2015-16_Full_Book_Ebook.pdf

Mason, Andrew dan Lee, Sang-Hyop (2004), The Demographic Devidend and Poverty Reduction, "Seminar on the Relevance of Population Aspects or the Achievement of the Millennium Development Goals, Paper No. UN/POP/PD/2004/19, New York, NY, November 17-19, 2004.

Mason, Andrew (2003), Population Change and Economic Development: What Have We Learned from the East Asia Experience?" Applied Population and Policy 1 (1).

Mason, Andrew (2003) Capitalizing on the Demographic Dividend, Population and Poverty, Population and Development Strategies (8). New York: United Nations Population Fund: 39-48

Mason, Andrew, 2002. Population and Human Resource Trends and Challenges, Key Indicators of Developing Asian and Pacific Countries. Volume XXXIII. (Manila: Asian Development Bank.

McCarthy, Kevin F, 1999. "World Population Shifts: Boom or Doom?". RAND Program of Policy-Relevant Research Communication, Santa Monica CA.

Pool, Ian (2007) Demographic Dividends: Determinants of Development or Merely Windows of Opportunity? Ageing Horizon Vol 7: 28-35.

Prskawetz, Alexia and Thomas Lindh (Eds.), 2007. "The Relationship Between Demographic Change and Economic 
Growth in the EU'. Institute for Futures Studies, Stockholm, Swedia.

Ven, Rutger van der dan Jeroen Smith (2011), The Demographic Windows of Opportunity: Age Structure and SubNational Economic Growth in Developing Countries.

Lutz, Wolfgang dan Samir KC, 2013. "Demography and Human

Development: Education and Population Projection". Human Development Report UNDP (occasional paper)

Yashiro, Naohiro. 2003. "Demographic Changes and their Implications for Japanese Household Savings," Stern ed., Japan's Economic Recovery, Edward Elgar Publishing Limited. ., 2011. "Indonesia Intergovernmental Transfer : Response on Future Demographic and Urbanization Shifts". Decentralization Support Facility. ...2015. "Analisis Bonus Demografi Sebagai Kesempatan Memacu
Perpercepatan Industri di Indonesia, Departemen Kajian dan Aksi Strategis BEM FEB UI"

, 2015. "National Skill Development Mission: Reaping the demographic dividend in India, (http://govenableresearch.com/blog/20 15/7/15/youth-skills-andentrepreneurship-reaping-thedemographic-dividend-in-india). , Indonesia Harus Manfaatkan Bonus Demografi Seperti Korsel, http://bisnis.liputan6.com/read/230706 7/indonesia-harus-manfaatkan-bonusdemografi-seperti-korsel

,Keadaan Angkatan Kerja Indonesia, ,http://www.bps.go.id/website/pdf_pu blikasi/watermark\%20_Keadaan_Ang katan_Kerja_di_Indonesia_Agustus_2 014.pdf 